\title{
Testing of vapour chamber used in electronics cooling
}

\author{
A. Haddad $^{1}$ R. Boukhanouf ${ }^{1} \&$ C. Buffone ${ }^{2}$ \\ ${ }^{1}$ University of Nottingham, Nottingham, UK \\ ${ }^{2}$ Thermacore Europe, Ashington, UK
}

\begin{abstract}
This paper presents experimental measurement of performance of a vapour chamber (VC), also known as a flat plate heat pipe, for electronics cooling. The vapour chamber, with square sides of $40 \times 40 \mathrm{~mm}$ and thickness of $3 \mathrm{~mm}$, was sandwiched between a heater block and a cooling plate located on the evaporator and the condenser surface respectively. The performance of the vapour chamber was investigated by determining the thermal resistance over a heat input range of 10 to $100 \mathrm{~W}$ with the condenser held at constant temperature. Test results for two vapour chambers with sintered and mesh type wicks were presented, and then compared to results obtained from tests on identical solid copper samples of 1 and $3 \mathrm{~mm}$ base thickness.

The experimental results show that the vapour chamber with sintered wick material performed markedly better than solid copper base at high heat fluxes, with vapour chamber orientation having minimal effect. On the other hand, the vapour chamber with a mesh wick showed no improvement compared to the $3 \mathrm{~mm}$ solid copper base and its performance decreased at high heat fluxes, particularly when operated against gravity. The test-rig set up as well as the experimental results will be presented in detail.
\end{abstract}

Keywords: vapour chambers, flat plate heat pipe, planar heat pipe, thermal management, electronics cooling, heat spread, high heat flux.

\section{Introduction}

Research and development on Heat pipes began in the early 1960s when it was mainly oriented towards space applications operating under micro-gravity conditions. Since then, heat pipe development has undergone steady progress 
with application in thermal management of many engineering systems such as spacecraft, chemical engineering, and electronics cooling [1,2]. In its simplest form, a heat pipe is a vacuum sealed vessel with a porous metal wick lining its interior wall and saturated with a working fluid such as water, ethanol, methanol, etc. In operation, heat is applied to one end of the vessel, the evaporator, to evaporate the working fluid from the wick, the vapour then travels to the cooler end of the vessel, the condenser, where it gives up its latent heat and condenses to liquid state. Under the capillary force of the wick, the liquid is returned back to the evaporator and the cycle continues. This cycle of a two-phase working fluid process allows high heat fluxes to be conducted through the heat pipe.

Heat pipes exist in simple configurations such as straight pipes or in more complex embodiments such as vapour chambers. In electronics cooling, vapour chamber heat pipes are becoming established thermal elements capable of transferring high heat fluxes from a single to multiple heat generating sources. The inadequacy of existing heat removal techniques (air cooling using fan-heat sink) for use in modern high speed microprocessors means that thermal management has become a critical technology, and it directly influences cost, reliability, and performance [5].

Vapour chambers are commonly integrated into the base of heat sinks as depicted by Figure 1 [3]. This combination of a vapour chamber and a heat sink into a cooling assembly would maintain multiple heat generating components mounting plate isothermal whereas standard heat sinks or cold plates would develop uneven heat distributions, dissipate high heat fluxes, eliminate hot spots and decrease weight of heat sink (by reducing the thickness of heat sinks base) as this arrangement would no longer require the base material to spread the heat.

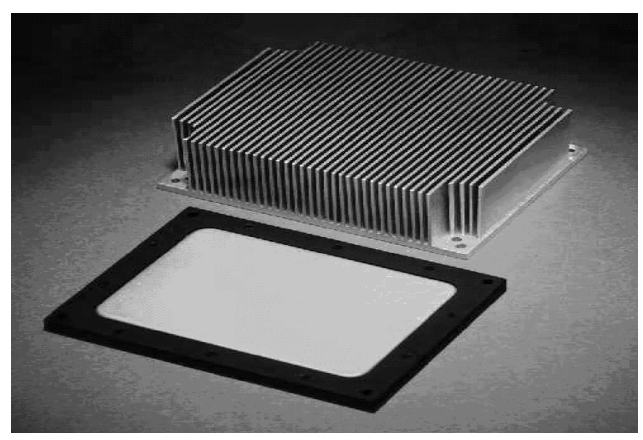

Figure 1: Vapour chamber used to spread heat across base of a heat sink (courtesy of Thermacore International).

The aim of this work is to measure performance of a mini-flat plate heat pipe approximately $40 \times 40 \mathrm{~mm}$ and $3 \mathrm{~mm}$ base thickness. The study will involve benchmarking a simple copper block, a vapour chamber with a sintered wick material and a screen mesh wick structure. 


\section{Experimental setup}

The VC heat pipe experimental rig assembly consists of a vapour chamber heat pipe, cold plate with liquid chiller unit (providing water flow at $35^{\circ} \mathrm{C}$ ), an electric heater, as shown in Figure 2.
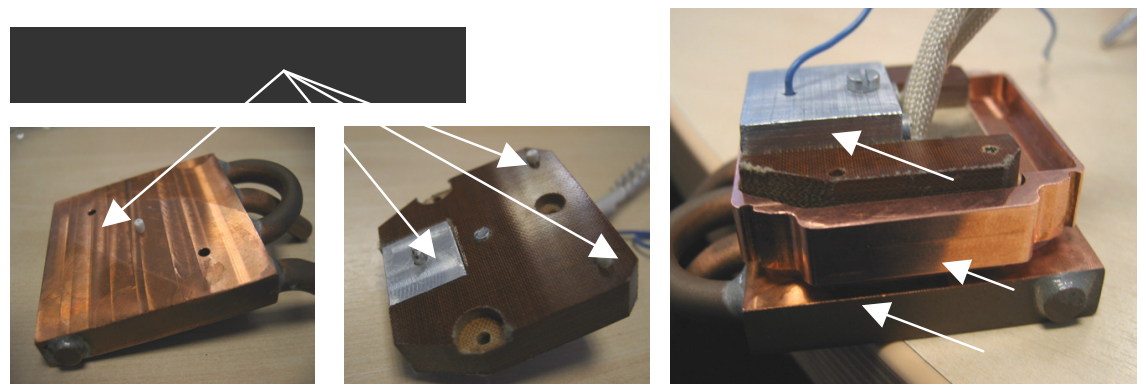

Figure 2: $\quad$ Test unit setup assembly.

Figure 3 shows a simple diagram of the vapour chamber heat pipes used as test samples in this experiment. The units were made from copper material in which the evaporator and condenser have a rectangular surface shape of $40 \times 40 \mathrm{~mm}$, with a $3 \mathrm{~mm}$ thick base. In this experimental arrangement, heat from the heater block is supplied from the top surface (i.e., the evaporator) and hence efficient capillary design of the wick materials is essential to overcome gravity forces acting on returning liquid. The sintered VC inner surface of the evaporator is covered with a sintered powder wick to provide capillary forces for the working fluid to be drawn into the heat supply region. Posts span the evaporator and condenser surface and serve as structural supports against externally applied forces. These maintain the small gap between the two surfaces. The mesh VC uses a coarse mesh at its core with a fine mesh wrapped around it. The fine mesh forms the wick material while the coarse mesh acts as a structural support to maintain the vapour space, as well as exert a pressure force to keep the fine wick pressed against the copper walls of the chamber.
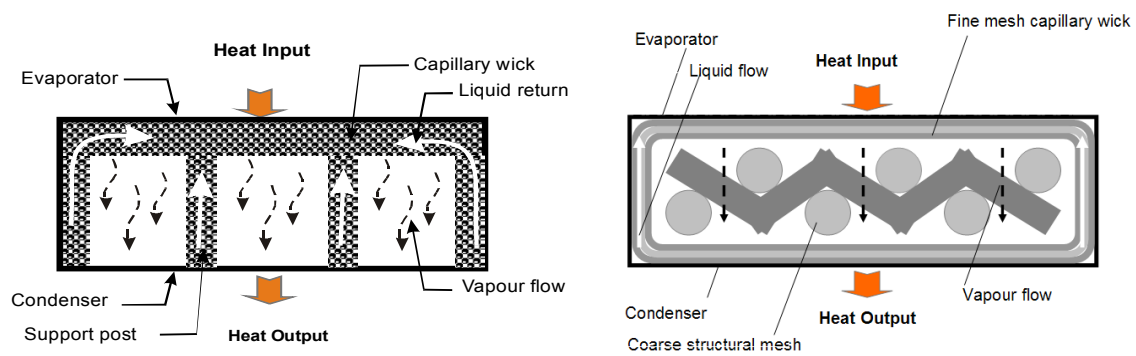

Figure 3: A simplified schematic diagram a) Sintered wick b) Mesh wick. 
Figure 4 shows the experimental set up and associated data acquisition instruments including thermocouples, a flow meter, and a data logger. For a comparative study, tests were conducted on solid copper samples, as well as both sintered and mesh wick vapour chambers to determine relative performance enhancement.

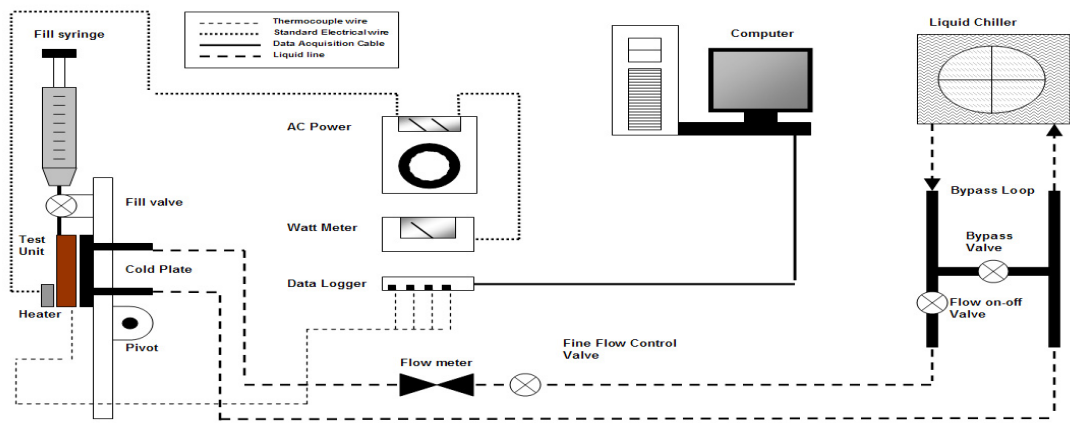

Figure 4: Experimental test rig.

The experimental procedure involved clamping the test unit between a cold plate and a heater block. Power was delivered though a controlled power supply to two electric heater cartridges placed inside an Aluminium block of 10x10mm dimension. To reduce contact thermal resistance, a layer of $0.5 \mathrm{~mm}$ thick thermal interface material of $6 \mathrm{~W} / \mathrm{mK}$ thermal conductivity was inserted between the base of the aluminium heater block and the VC evaporator surface, as well as between the condenser side and the cold plate. The performance of the VC was evaluated for various heat loads by using a variable electric power source to supply heat to the heater block. A wattmeter was also used to accurately measure the power supplied. Initial heat input to the $\mathrm{VC}$ was set at $10 \mathrm{~W}$ and then increased at equal increments up to $100 \mathrm{~W}$. At each power level, the experiment was allowed to run for about 5 minutes so that heat transfer steady state in the $\mathrm{VC}$ was reached. The maximum heat supply to the test unit was limited to the $\mathrm{VC}$ surface temperature approaching the $100^{\circ} \mathrm{C}$ threshold, above which internal pressure becomes too high and the chamber could be damaged. A filling/venting system was used to accurately fill the required amount of working fluid. The test sample was also mounted on a rotating beam which allows testing to be carried out at tilt angles ranging from $0^{\circ}$ to $180^{\circ}$. In this work, the VCs were tested at 3 orientations $0^{\circ}$, $90^{\circ}$, and $180^{\circ}$.

Charging of the vapour chambers was achieved by first venting air from a dry unit using a vacuum pump. A fill syringe containing deionised water was attached to the vapour space of the VC through a valve, which when opened allows liquid into the evacuated chamber. The heater was then switched on so that the working fluid is brought to boiling to purge any non-condensable gases from the chamber. After that the fill tube was crimped and the camber sealed without losing its vacuum. 


\section{Results and discussion}

The experimental results of both sintered and mesh VCs at $0^{\circ}, 90^{\circ}$, and $180^{\circ}$ orientations, and solid copper blocks with $1 \mathrm{~mm}$ and $3 \mathrm{~mm}$ base thickness are presented in graphical format. The heat load applied to the VCs was ramped up to a maximum of $100 \mathrm{~W}$ at all orientations.

The graphical plots show the test units surface temperature over a period of time and at various levels of heat input, as well as, the temperature difference between the heater and condenser/corner temperatures. The graphs also depict the transient regime of heat transfer in the test unit at the designated monitoring points on the surface of the test unit sample. The recorded data subsequently used to determine the spreading resistance of all test unit samples (i.e., a sintered $\mathrm{VC}$, mesh VC, and solid copper).

\subsection{Solid copper}

Two solid copper equivalents to the vapour chambers were built and tested in order to provide benchmark results. The copper units tested had $1 \mathrm{~mm}$ and $3 \mathrm{~mm}$ base thickness. Figures 5(a) and (b) below show the temperature plots from those units. As can be seen, the thicker $3 \mathrm{~mm}$ copper base produced lower temperature difference to the $1 \mathrm{~mm}$ unit. This can be expected as the thicker material will improve heat spread across the base, therefore improving heat input into the adjacent cold plate. Results are linear across the full power range, demonstrating the materials' constant conductivity.
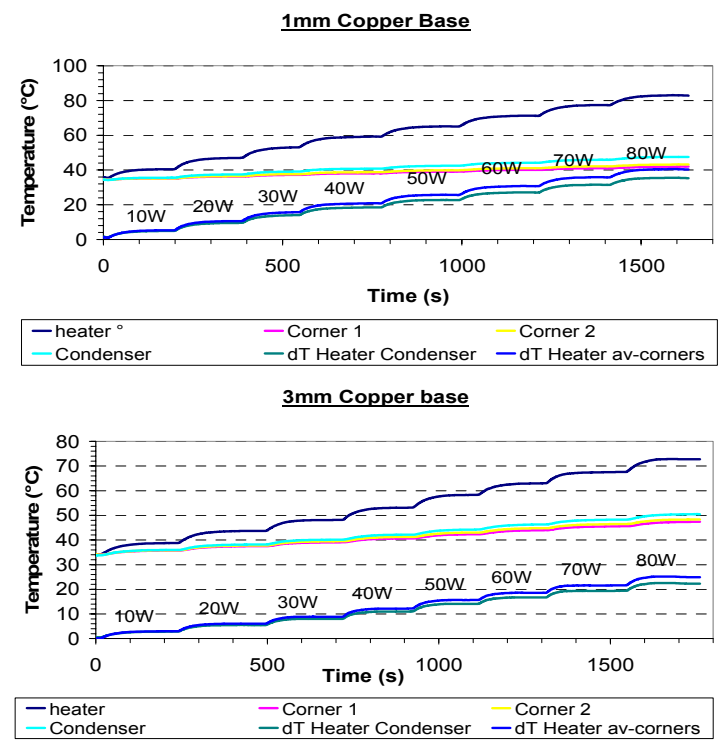

Figure 5: $1 \mathrm{~mm}$ and $3 \mathrm{~mm}$ base copper transient state over several heat inputs. 


\subsection{Sintered VC}

The sintered wick vapour chamber was tested at various orientations with graphical results illustrated on figures $6(\mathrm{a}),(\mathrm{b})$, and (c). The overall performance demonstrated a reduced temperature difference over copper, particularly at the higher power levels. The performance is not significantly affected by the orientation, as can be expected from the higher capillary forces in sintered wicks [1].

A drop in heater temperature can be seen in all three curves at the highest power level. Overall this translates into improved performance as the temperature difference between the heater and the condenser/corners is reduced as a result. It is likely that the fill volume may not have been optimal. An overfill situation would have resulted in flooding which will impair performance up to a certain higher power level when this excess liquid is evaporated. Further investigation will be needed to determine the exact nature of this occurrence.

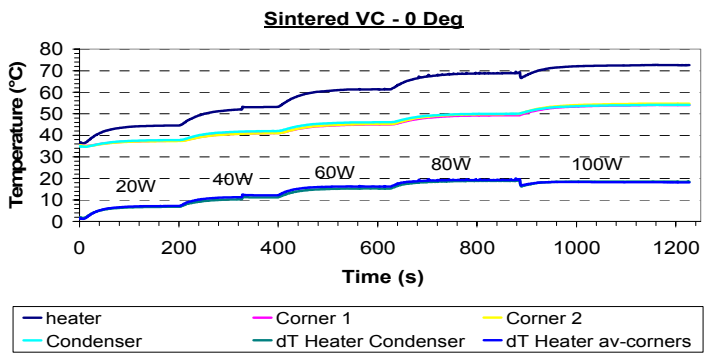

Sintered VC - 90 Deg

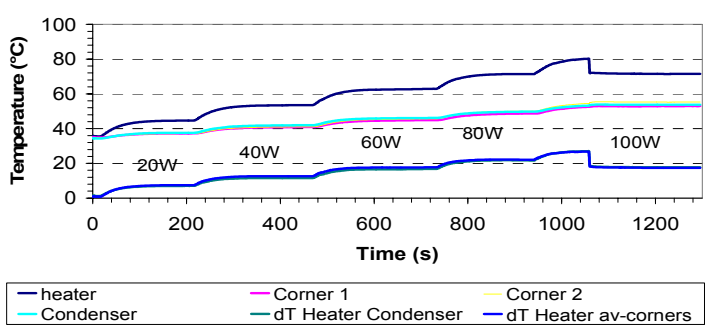

Sintered VC - 180 Deg

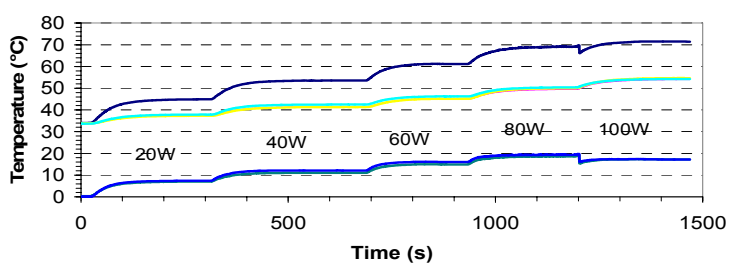

\begin{tabular}{|lll|}
\hline - heater & - Corner 1 & - Corner 2 \\
- Condenser & - dT Heater Condenser & - dT Heater av-corners \\
\hline
\end{tabular}

Figure 6: $\quad$ Sintered VC transient state over several heat inputs $-0^{\circ}, 90^{\circ}$, and $180^{\circ}$ orientation. 


\subsection{Mesh VC}

Test results for the mesh wick vapour chamber are illustrated in figures 7(a), (b), and (c). The performance curves show a temperature difference between heater and corner/condenser temperatures being markedly higher than the sintered vapour chamber. Furthermore response to the orientation was more sensitive, with a clear dry out condition taking place at $80 \mathrm{~W}$ in the $90^{\circ}$ orientation (fig. 7(b)).
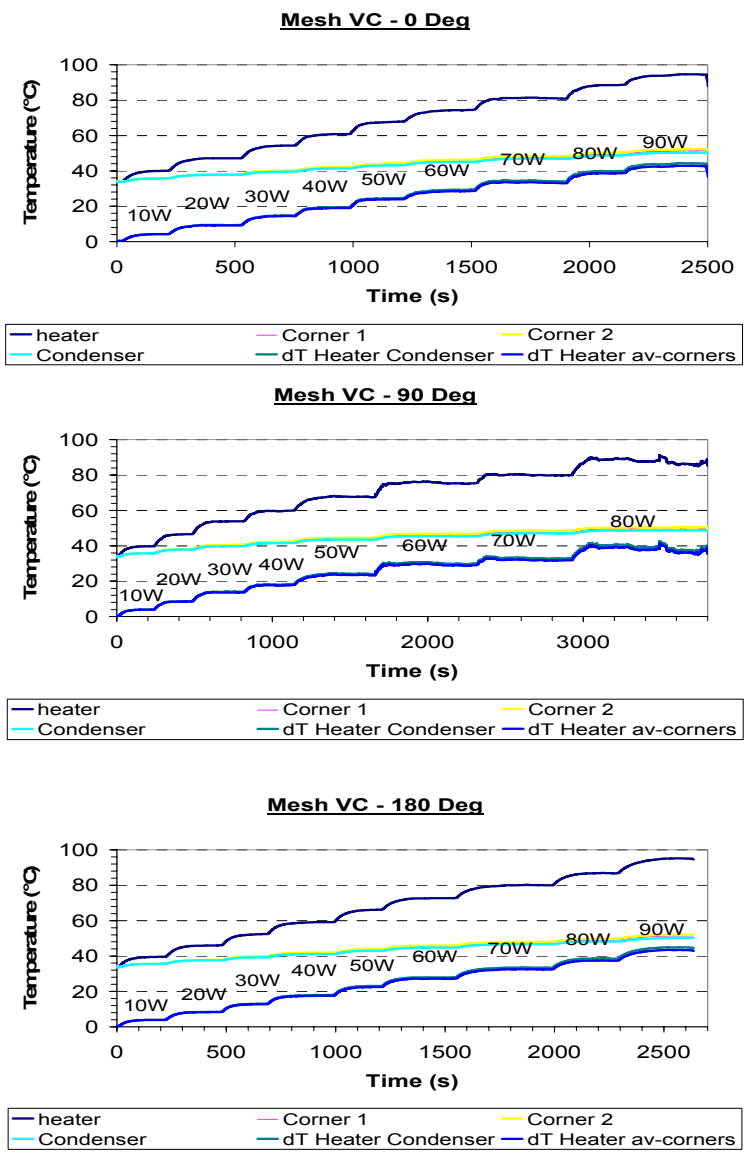

Figure 7: Mesh VC transient state over several heat inputs $-0^{\circ}, 90^{\circ}$, and $180^{\circ}$ orientation.

\subsection{Thermal and spreading resistance}

In order to gain further insight into the performance measurements of the test units, thermal and spreading resistance were evaluated. Thermal resistance was 
taken as the temperature difference between the heater and the condenser divided by the power input (1).

$$
R_{T}=\frac{T_{\text {Heater }}-T_{\text {Condenser }}}{Q_{\text {in }}}
$$

Spreading resistance was taken as the difference between the heater and the average of the two corner temperatures, divided by the power input (2).

$$
R_{S}=\frac{T_{\text {Heater }}-\frac{T_{\text {Corner } 1}+T_{\text {Corner } 2}}{2}}{Q_{\text {in }}}
$$

The Thermal and spreading resistance for all test units are presented graphically in Figures 8(a) and (b).
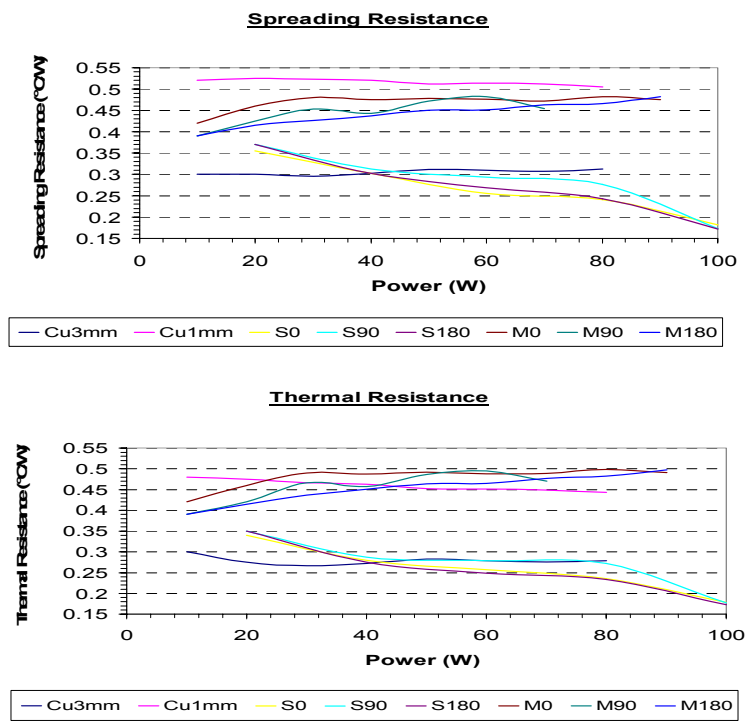

Figure 8: Thermal and spreading resistance for test units across full input power range.

As can be seen, $3 \mathrm{~mm}$ copper performs significantly better than $1 \mathrm{~mm}$ copper. The Mesh is slightly better than $1 \mathrm{~mm}$ copper but is unable to surpass the performance of $3 \mathrm{~mm}$ copper.

All mesh curves are roughly equal, but as can be expected, the $90^{\circ}$ unit did not continue to perform as well as the $0^{\circ}$ and $180^{\circ}$ orientations. Dry out occurred at approximately $70 \mathrm{~W}$. This condition is more clearly seen in the corresponding graph in figure $7 \mathrm{~b}$.

The sintered units were far better than the mesh with curves equalling those of $3 \mathrm{~mm}$ copper at $40 \mathrm{~W}$ and surpassing them from that point on. At $80 \mathrm{~W}$ the 
performance received a sudden surge which ultimately resulted in a resistance of $1.5 \mathrm{C} / \mathrm{W}$ less than $3 \mathrm{~mm}$ copper. A further insight here was that these units did not indicate any dry out condition and showed little effect to gravity. The $90^{\circ}$ unit was marginally worse in resistance, as the curves indicate.

The experimental results presented here did not take into account heat loss from test units through convection and radiation and the electric power supplied to the heater block was assumed to be fully converted by Ohmic effect into heat and transferred through the body of the test unit to the liquid cold plate. More refined experimental measurements which take heat losses into account through the use of a heat balance will be conducted. The heat balance can be obtained from measurement of liquid flow rate and temperature difference between the input and output flow of the cold plate. Additionally, tests with varying degrees of liquid fill, different grades of sintered wick, and methanol as working fluid will also be conducted to expand the scope of this research.

\section{Conclusion}

The main objective of this study was to investigate performance enhancement of integrating a small vapour chamber, approximately $40 \times 40 \mathrm{~mm}$ in span, into an electronics cooling application. The heat source was approximately $10 \times 10 \mathrm{~mm}$ in size delivering a maximum of 100 Watts heat energy.

Subsequent testing of sample units was conducted, at power levels of $10 \mathrm{~W}$ to $100 \mathrm{~W}$. These implemented a specially designed heater block and liquid cold plate, taking temperature readings at various surface points. Both mesh and sintered wick vapour chambers were tested with $3 \mathrm{~mm}$ base thickness against solid copper units with a $1 \mathrm{~mm}$ and $3 \mathrm{~mm}$ base thickness. Performance was measured by reading the temperature difference between measurement points and calculating the corresponding thermal resistance.

Overall it became evident that an improvement could be gained from the sintered units, exceeding the performance of the copper samples, increasing power input lead to further improvements. After $40 \mathrm{~W}$ power input the sintered units marginally outperformed the $3 \mathrm{~mm}$ copper. After $80 \mathrm{~W}$ power input the sintered units significantly outperformed the $3 \mathrm{~mm}$ copper with consistent improvement over the full power range and no dry out condition. Orientation did not affect the performance significantly.

Mesh units did not show an improvement over the $3 \mathrm{~mm}$ base copper, furthermore, their performance degraded as power input increased and orientation turned against gravity. Dry out was experienced with mesh at $70 \mathrm{~W}$ at an orientation of $90^{\circ}$.

\section{References}

[1] Dunn P.D. and Reay D.A., 1994, Heat Pipes, 4th ed., Pergamon Press Ltd., New York.

[2] Groll M., Heat pipe research and development in Western Europe. Heat Recovery Systems and CHP Vol. 9 No. 1 (1989) 
278 Advanced Computational Methods in Heat Transfer IX

[3] Lee, S., Calculating Spreading Resistance in Heat Sinks, Electronics Cooling, Vol. 4 No. 1, 1998, pp. 30-33.

[4] Kaplan H., 1993, Practical Applications of Infrared Thermal Sensing and Image Equipment, O’Shea, Series Editor, Georgia Institute of Technology, USA.

[5] Moore, G. E., Cramming More Components Onto Integrated Circuits, Electronics, Volume 38, Number 8, April 19, 1965 